\title{
Pituitary Gland Microadenoma
}

National Cancer Institute

\section{Source}

National Cancer Institute. Pituitary Gland Microadenoma. NCI Thesaurus. Code C43541.

A pituitary gland adenoma with a diameter equal or less than $10 \mathrm{~mm}$. 